\title{
A POÉTICA DO SILÊNCIO EM MARCOS SISCAR
}

\author{
Annita Costa Malufe
}

\begin{abstract}
RESUMO
$\mathrm{O}$ artigo apresenta a concepção de silêncio contida na poética de Marcos Siscar (1964-) a partir do diálogo com pensadores e artistas do século XX: um silêncio do excesso, no lugar do silêncio transcendente e inalcançável das poesias romântica ou metafísica. O objetivo é mostrar de que potência esta mudança de paradigma do silêncio poético nutre a leitura de seu poema.
\end{abstract}

PALAVRAS-CHAVE: poesia contemporânea, Marcos Siscar, silêncio.

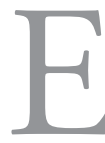

m 2006, o poeta paulista Marcos Siscar lança seu livro $O$ roubo do silêncio. Para aqueles que já conheciam o anterior Metade da arte, de 2003 - que juntava a uma nova série de poemas toda sua obra até então -, O roubo do silêncio trazia uma novidade formal logo notada. Em lugar de poemas em versos, um livro todo em poemas em prosa, ou prosa poética; em lugar de uma poesia que explora o corte, a fragmentação, algo mais contínuo, menos interrompido. Estaríamos diante de textos mais discursivos e, portanto, menos silenciosos? Seria este o "roubo"? É talvez o que o formato da obra e seu título nos levem a questionar. Haveria mais silêncio na linha interrompida, no verso curto, do que na linha da prosa, ou no fluxo (aparentemente) ininterrupto de um parágrafo?

Em uma entrevista concedida ao programa Entrelinhas da TV Cultura, Marcos Siscar explica o título de seu livro:

$O$ roubo do silêncio para mim é o roubo da poesia, assim digamos, é o roubo da felicidade de poder ficar em silêncio. Minha poesia fala muito de silêncio, da vontade de chegar até o silêncio. 
Então tem aí uma espécie de paz que está no silêncio e que dentro da minha vida e dentro da minha escrita são coisas que eu considero que foram roubadas. ${ }^{1}$

É preciso manter o silêncio, recuperá-lo. Restituí-lo ali onde ele parece ter sido roubado. Pode parecer paradoxal que esta declarada busca pelo silêncio se dê de modo ainda mais verborrágico do que em seu livro anterior. $\mathrm{Ou}$ seja, que a questáo do silêncio ganhe relevo, justamente, em um livro que troca os cortes dos versos pela pontuação da frase. Podemos logo nos lembrar que Marcos Siscar segue uma busca explícita no sentido da experimentação de outras formas de versificar, de cortar, ou ainda, de fazer a poesia respirar. E isto à maneira de uma consciente reflexão na esteira mallarmeana acerca do corte. Como diz Mallarmé, em um texto bastante conhecido, o verso estaria presente em qualquer texto em que houvesse ritmo, fosse ele considerado prosa ou poesia. ${ }^{2}$ Em outra entrevista, Siscar explica:

Não quis abdicar do verso [em $O$ roubo do silêncio], mas reinterpretar os seus cortes, suas interrupçóes, suas repetiçóes, seus colapsos, seus lancinamentos. O que eu chamo de verso não se reduz à linha interrompida. Acho que a interpretação que os poetas concretos fizeram sobre a questão do verso em Mallarmé é pobre, nesse sentido. ${ }^{3}$

A opção nesta sua obra é também por textos que trazem algo de reflexivo, muitas vezes avizinhados da linguagem filosófica ou ensaística. Esta "vocação" que muitos veem na poesia de Siscar, já desde os livros anteriores, ganha aqui uma presença maior. O que se explicita, neste movimento, é a dupla face desta poesia, ou a dupla pesquisa que ela encarna. Uma pesquisa que é, simultaneamente, poesia e pensamento, poesia que se faz ao mesmo tempo em que constitui um modo singular de pensar. Ou que pensa ao mesmo tempo em

1 SISCAR, Marcos. Entrevista para o programa Entrelinhas (transcrição). São Paulo: TV Cultura, ao ar em 06/09/2006.

2 MALLARMÉ, Stéphane. Poésies et autres textes. Paris: Le Livre de Poche, 1998, p. 242.

3 MALUFE, Annita Costa. "Entrevista com Marcos Siscar”. In: Poéticas da imanência: Ana Cristina Cesar e Marcos Siscar. Rio de Janeiro/ São Paulo: Ed7Letras/ Fapesp, 2011, p. 253. 
que se faz, em que é escrita. Talvez o avizinhamento com a filosofia em Siscar, assim, não esteja somente no fato do poeta ter realizado seu doutorado acerca da escrita de um filósofo, Jacques Derrida, ou de sabermos que em seus artigos teóricos ele tenha como referencial a filosofia, mas, antes, no fato de estarmos diante de uma poesia que cria com ela toda uma poética e explicita esta criação de modo mais contundente. Poesia que é criada em simultaneidade à criação de um pensamento, de uma concepção de mundo, de vida e de poesia.

Há portanto um pensamento sobre o silêncio operando junto com esta poesia. O "silêncio" no título não é uma palavra aleatória ou ornamental, apenas. $\mathrm{O}$ que não implica, por outro lado, em dizer que haveria aí uma poesia teórica, que reflete "sobre" o silêncio, ou sobre o que quer que seja. Mas sim, que aí temos um pensamento em construção, uma poética que é a própria construção deste pensamento, deste modo de ver, conceber, sentir, viver. De modo que estamos diante de uma poesia que talvez crie consigo, no seu percurso, sentidos próprios para certas palavras. Sentidos que corroboram com modos de viver e ver as coisas, e portanto, de conceber a própria poesia ou a arte.

Mas que silêncio é este de que trata a poesia de Siscar? Como vemos no texto que leva o título do livro, "O roubo do silêncio" equivaleria ao roubo da morte. Formulaçáo que pode nos soar estranha: o que seria exatamente o roubo da morte? A morte, por si, não seria, ela sim, o roubo da vida? Mas o fato novo aqui é esta curiosa aproximação entre silêncio e morte. Não apenas no sentido mais esperado, da morte como o silenciamento da vida, mas da íntima relação do silêncio com este acontecimento limite, que não nos pertence nem jamais pertencerá. $\mathrm{O}$ silêncio como o abismo que contém, no limite, a presença de nosso maior e derradeiro abismo. O silêncio enquanto silenciamento subjetivo que nos constitui e vai-se infiltrando em nós. Vejamos dois trechos deste poema, ou prosa poética: ${ }^{4}$

Quando minha morte náo me pertence, o modo de morrer não me pertence, esse expatriamento vai entrando dentro da vida. Quando minha morte me é roubada, é o roubo que corre para dentro de mim. (...)

4 SISCAR, Marcos. O roubo do silêncio. Rio de Janeiro: Ed. 7Letras, 2006, p. 19. 
O silêncio é o sofrimento da palavra, quando a poesia do silêncio lhe é roubada. A vingança dos desapropriados é o barulho da prosa do mundo. Se eu pudesse falar, pegaria andorinhas em pleno voo.

Somos “desapropriados" por natureza, nossa morte nos é roubada, talvez logo ao nascermos. Talvez ela nem mesmo possa um dia nos pertencer, uma vez que ela é o ápice de um puro abandono ou de um "expatriamento" do sujeito, um despertencimento de fundo que "vai entrando dentro da vida", como lemos no primeiro trecho selecionado. Talvez já nasçamos roubados, expatriados, ou talvez só nasçamos mesmo por este expatriamento inicial, esta fuga inicial, que consiste em um corte a-subjetivo. Afinal, jamais se nasce ou se morre por um gesto voluntário de um sujeito que escolhe e opta por seu próprio nascimento ou morte. Somos, por definição, desapropriados daquilo que nos acontece: não somos donos ou sujeitos atuantes em nossa morte.

Essas sugestóes contidas nas palavras de Siscar podem nos remeter a uma bela ideia de Maurice Blanchot. Para o filósofo e escritor, a morte é o grande limite em que se dá o apagamento do sujeito. Como diz Blanchot, não há como sermos proprietários de nossa morte, nem mesmo no suicídio (que traria implícita esta vontade) quando escolhemos o modo e o momento de morrer. $\mathrm{Na}$ morte somos absolutamente destituídos do poder de dizer "eu" - afinal, como dizer "eu morro" ou "eu morri"? A morte apareceria, portanto, como o derradeiro instante do silenciamento subjetivo. Ou da impotência do sujeito frente à emergência da vida, aos acontecimentos que o tomam. Limite este que pode nos assombrar ou nos fascinar: o grande corte que nos pertence intimamente sem nunca ser efetivamente "nosso". É então na intimidade desta destituição, deste exílio, que viveria aquele que foi roubado: "é o roubo que corre para dentro de mim”, diz Siscar. O homem é povoado por um roubo inicial, que é o roubo de sua morte, roubo que o faz desapropriado, por conseguinte, de sua própria vida e da possibilidade de enunciá-la em nome próprio.

Os desapropriados parecem ser, no dizer de Siscar, os próprios poetas, aqueles de quem a "poesia do silêncio" também foi roubada. Mas estes seres destituídos do silêncio da poesia não caem, como se poderia esperar, na mudez, esse outro tipo de silenciamento que seria, em seus termos, um "sofrimento da palavra". O que eles devolvem como "vingança” seria "o barulho da 
prosa do mundo". O que eles devolvem é a possibilidade de uma palavra que já não é mera afirmação subjetiva, individual, não é o falar em nome próprio, mas sim, uma palavra que parece nascer justamente deste roubo, da perda de sua plena autoafirmação. É uma "prosa do mundo" e não mais uma palavra do sujeito.

Dessa forma, a "vingança" poética, a fala dos exilados, nasce da intimidade com a morte, nasce da intimidade com este extremo de impotência do sujeito. Impotência esta que é a de todos nós, seres viventes. É uma palavra que nasce e retorna ao silêncio, ou à morte enquanto ápice do silêncio. Desta condição de vizinhança estreita com a morte, é como se o poeta tirasse a possibilidade de uma palavra que acolhe "esta morte pulsante que é o coração de cada um de nós", para tomarmos os termos de Blanchot. ${ }^{5}$ Uma palavra, portanto, que só poderia ser silenciosa, que só poderia nascer de dentro do próprio silêncio.

Blanchot insiste na ideia desta intimidade do artista, do escritor, do poeta com este extremo, que teria como ponto culminante a morte, mas que também aparece nas figuras do exterior ou o fora (enquanto forças futuras, imprevistas), da ausência dos deuses, do silêncio, da noite, do abismo, do acaso. Chegando a afirmar: "Quem sonda o verso morre, reencontra sua morte como abismo". ${ }^{6}$ Quem sonda o verso rodeia a morte, mas com a decisão de não ser devorado por ela, como Kafka que "voa ao redor da morte, ele náo se queima nela, mas ele torna sensível a queimadura". 7 Tornar sensível a morte, a queimadura da morte, na arte, seria algo como tornar sensível este silêncio que não é meramente um silêncio de falta de som ou de vazio empírico. Tampouco deve ser confundido com um silêncio mórbido, ou melancólico: ele é antes o silêncio do náo-senso, do incerto, do movimento que pode emergir, imprevisto - o silêncio do voo das andorinhas.

Entâo a saída para este roubo não é uma mudez ou uma lamentação, não é uma melancólica saudade de uma origem perdida, mas é antes, na expressão de Siscar, uma "alegria de palavras", uma festa do excesso de sentido, em que a alegria vem, justamente, entre o deslocamento do se achar dono de tudo e, em seguida, notar que tudo trafega muito acima de sua vontade:

\footnotetext{
5 BLANCHOT, Maurice. L'Espace littéraire. Paris: Gallimard/ Folio, 1955, p. 145.

6 Idem, p. 38.

7 Idem, p. 113.
} 


\section{Traduzido do poeta quando jovem quando chove a chuva é para todos as nuvens da tarde elefantes cegos vistas da janela são retratos do dia chove e tudo só depende de mim olhos sem mágoa sem esperança não nada será como antes só o decreto do gesto chove e tudo independe de mim tudo fora de mim em constrangedora alegria trafega (se na janela um riso?) quando chove a chuva é para todos salvo se a chuva (nota bene) sucede uma manhã banhada de sol $^{8}$}

A “constrangedora alegria” vem, assim, após o deslocamento dessas constataçóes - do "chove e tudo só depende de mim" e, dois versos abaixo, o "chove e tudo independe de mim", o paralelismo acentuando esta metamorfose do poema e do poeta. Tudo independe de mim e o que resta desta constatação não é um lamento ou uma desistência, mas uma alegria, uma espécie de acolhimento daquilo que me escapa das mãos. Um acolhimento do que não conheço e do que pode vir, sem que eu saiba ou espere: um sorriso que entra pela janela, a chuva que independe de mim: "tudo fora de mim em constrangedora alegria trafega (se na janela um riso?)”.

A saída para se ter de volta um pouco do silêncio roubado é portanto falar e falar, é criar uma nova fala que acolha a possibilidade deste outro silêncio. Silêncio que nos remeteria, quem sabe, ao "silêncio que não é mudez", de que fala a poeta Ana Cristina Cesar em um de seus poemas de $A$ teus pés: "Frente a frente, derramando enfim todas as palavras, dizemos, com os olhos, do silêncio que não é mudez. (...)" ${ }^{9}$ Ou ainda, a busca por se falar de dentro do silêncio, para a ele poder retornar. Falar e falar para, aí sim, conseguir um silêncio perfeito, como no dizer de Alejandra Pizarnik: "Ainda que diga sol e

8 SISCAR, Marcos. Metade da arte. São Paulo/ Rio de Janeiro: Cosac Naify/ Ed. 7Letras, 2003, p. 29.

9 CESAR, Ana Cristina Cesar. A teus pés. São Paulo: Ática, 1999, p. 54. 
lua e estrela refiro-me a coisas que me acontecem./ E o que desejava eu?/ Desejava um silêncio perfeito./ Por isso falo.", diz um poema de Extracción de la piedra de la locura, de $1966 .{ }^{10}$

A aproximaçáo da poética de Siscar com essas outras poéticas e com a filosofia de Blanchot me parece pertinente no sentido de encontramos nessas propostas uma noção de silêncio enquanto excesso e não enquanto falta ou impossibilidade. Nessas, e em algumas outras poéticas a partir do século XX, o que se sobressai é uma possibilidade de se conceber um silêncio que já náo é o silêncio transcendente, inalcançável - seja ele Deus ou mesmo humano, no sentido de sentimentos ou coisas mudas às quais as palavras náo teriam acesso. Como afirma Fabio Weintraub, que intitula seu artigo sobre Siscar de "Silêncio profano", este silêncio nada tem a ver com um indizível transcendente, divino ou místico. Este silêncio se relaciona, antes, a uma questấo de linguagem, a um questionamento de ordem, muitas vezes, metalinguística:

(...) sua defesa do silêncio contra 'o alarde da memória' não pode, de modo algum, ser encarada como uma espécie de refúgio nos confins do absoluto indizível, pois, mesmo nos poemas mais ostensivamente metalinguísticos, há elevada dose de inconformismo e ironia desfazendo qualquer pose metafísica. ${ }^{11}$

Aproximamo-nos aqui, assim, de um silêncio que só pode ser achado entre as palavras, e que no lugar de estar voltado a um passado - um silêncio que já está aí ou que sempre aí esteve (nas coisas ou em Deus) -, volta-se a um futuro que não cessa de nos chegar, que não deixa jamais de precipitar-se em nós, a todo instante.

Esta presença do silêncio a partir do excesso já se fazia sentir nos poemas anteriores de Siscar, de Metade da arte. Muitos desses poemas, em especial aqueles do livro anterior aí incluído Não se diz e da última série homônima "Metade da arte", se fazem a partir de volteios e reiteraçóes, em um movimento que o poeta Michel Deguy definiu como o de fazer rodeios ou rodear algo

10 PIZARNIK, Alejandra. Poesía completa. Barcelona: Lumen, 2004, p. 243, trad. livre.

11 WEINTRAUB, Fabio (2000). "Silêncio profano". In: Revista Cult. São Paulo, setembro, p. 38-39. 
que se esquiva: "tourner autour du pot", diz ele, no prefácio a Não se diz. Há muitas vezes um giro de palavras, uma ciranda de repetições e retomadas, e o poema vai se fazendo como uma pequena ladainha, um giro que parece cercar um silêncio de significação:

\author{
Mau infinito \\ persiste a dor a dor não é \\ somente a erosáo artista \\ não se diz dor da dor despida \\ incapaz do hábito e da fratura \\ da dor a dor não se diz não \\ se diz seu não-dito não é mais \\ nem infinito não se diz dor \\ sem trair o que da dor se escorre \\ (sua voz frágil me comovia \\ meu deleite lhe era insulto) ${ }^{12}$
}

Falar é um recurso para, como diz Samuel Beckett, encontrar o silêncio por trás das palavras, fazer emergir o não-dito na superfície do que é dito. Como se a saída fosse falar para tornar sensível o silêncio roubado, este que é pura possibilidade e abertura ao sentido e que, paradoxalmente, só pode existir, para nós, com e entre as palavras. No limite, portanto, trata-se de falar para acolher, numa espécie de "passividade ativa", o acontecimento da morte, e, consequentemente, da vida: falar para captar o tempo, o movimento, para pegar “andorinhas em pleno voo". Pensando também na prosa poética de Beckett, com a qual a proposta de Siscar expressa fortes ressonâncias, há algo como o que o compositor John Cage diz em seu "Lecture on nothing" - poema cheio de lacunas e espaços em branco no qual a certa altura ele escreve: "What we re-quire is/ silence;/ but what silence requires/ is that I go on talking". ${ }^{13}$

É Cage, ainda, que nos fornece uma interessante imagem para pensar no silêncio como excesso. Para o compositor, as pausas entre uma nota e outra

12 SISCAR, 2003, op. cit., p. 83.

13 Em tradução livre: "O que pedimos é silêncio mas o que o silêncio nos pede é que continuemos falando”. CAGE, John. Silence. Middletown: Wesleyan University Press, 1973, p. 109. 
seriam um silêncio absolutamente "barulhento", uma vez que imediatamente preenchido pelos ruídos e sons do ambiente - sons que só seriam chamados de silêncio por não serem criados com uma intençáo musical. ${ }^{14}$ As pausas são a abertura que o compositor deixa na música para que ela se conecte com o exterior, ou ainda, para que este "fora" venha participar da sua obra. Abertura próxima ao que aconteceria na escultura e arquitetura modernas, como na arquitetura de vidro de Mies van der Rohe, nas esculturas de arame de Richard Lippold ou, poderíamos acrescentar aos exemplos de Cage, nas fendas das esculturas de Henri Moore. Como nas pausas musicais, esses buracos e transparências seriam o vazio necessário para que a paisagem exterior passe a fazer parte da obra, para que a obra se componha com o que a cerca: as pessoas que circulam, as árvores, a vegetaçáo, as nuvens, a rua, as mudanças de clima, tudo passa a ser parte da obra. Como ressaltam Deleuze e Guattari, trata-se do vazio necessário para que saltem cavalos - condição sem a qual não estaríamos diante de uma obra de arte: "Uma tela pode ser inteiramente preenchida, a ponto de que mesmo o ar não passe mais por ela; mas algo só é uma obra de arte se, como diz o pintor chinês, guarda vazios suficientes para permitir que neles saltem cavalos (...)." ${ }^{15}$

Em todos esses casos, como se vê, trata-se de um silêncio e um vazio que permitem que a obra se componha com elementos imprevisíveis ao artista na hora em que está criando - elementos libertos, ainda, de "intençôes artísticas". O que faz com que o silêncio apareça como uma brecha no interior da obra que o artista concede ao futuro da escuta, da visão ou da vivência que o público terá. Como se ele deixasse pontas soltas, sem ligaçôes ou relaçôes pré-concebidas, para que um pouco de ar puro possa passar. Vemos, assim, o quanto estamos diante de um silêncio mais próximo a um excesso de elementos (ainda que náo formados, em estado de indeterminaçáo, uma caótica de forças) do que de um puro vazio ou uma falta. Trata-se de um silêncio extremamente povoado - "o interminável, o incessante", como para Blanchot. ${ }^{16}$

${ }^{14}$ Idem, p. 22-23.

15 DELEUZE, Gilles e GUATTARI, Félix. O que é a filosofia? Trad. Bento Prado Jr. e Alberto Muñoz. São Paulo: Editora 34, 2000 (do original em francês Qu'est-ce que la philosophie?, 1991), p. 215.

16 BLANCHOT, 1955, op. cit., p. 20. 
É possível pensar que, empiricamente, haja uma impossibilidade de um silêncio puro - e apenas na morte, de fato, ele seria possível. Um pouco do que narra Cage acerca de sua experiência em uma câmara anecoica mesmo ali, isolado de qualquer ruído externo e qualquer eco, ele escutava dois sons ininterruptos, um grave e outro agudo: disseram-lhe (informaçáo correta ou náo) que o primeiro era o de sua circulação e o segundo de seu sistema nervoso. ${ }^{17}$ De todo modo, ao narrar esta experiência, Cage está procurando falar da impossibilidade do silêncio em si, algo do que vemos, ainda, no título de outro de seus poemas recolhidos em Silence: "I have nothing to say and I am saying it". ${ }^{18}$

Ou seja, mesmo quando nada se tem a dizer, este "nada a dizer" torna-se enunciado de alguma forma, ele acaba passando pela linguagem para fazer sentido para nós. Ainda se imaginarmos uma situação em que o "nada a dizer" não seja enunciado - que simplesmente estejamos diante de alguém que nada diz, por exemplo, em uma reunião -, veremos que rapidamente as pessoas presentes traduziriam esta atitude silenciosa, em voz alta ou não, como "fulano não tem nada a dizer", ou "fulano está em silêncio para que notem sua atitude de protesto", ou ainda "fulano é tímido", entre infinitas outras possibilidades. O que por um lado nos faz pensar, com Roland Barthes, na facilidade com que o silêncio torna-se signo, na velocidade com que ele é capturado pelas palavras e pelo sentido. ${ }^{19} \mathrm{E}$, por outro, faz-nos ainda notar que o próprio sentido do silêncio é algo que se faz com a linguagem, em relação com ela, o silêncio é algo que ganha sentido entre as palavras, a partir delas.

Da mesma forma na música. Como observa Deleuze na aula "Sur la musique" (de 08/03/1977), um silêncio em si seria algo inexistente, só podendo ser concebido no interior da música ou de um determinado agenciamento

17 CAGE, op. cit., p. 8.

18 Em tradução livre: "Não tenho nada a dizer e estou dizendo-o". Idem, p. 51.

19 “(...) o que é produzido expressamente para não ser signo é bem depressa recuperado como signo. É o que ocorre com o silêncio: quer-se responder ao dogmatismo (sistema pesado de signos) com alguma coisa que burle os signos: o silêncio. Mas o próprio silêncio assume a forma de imagem, de postura mais ou menos estóica, 'sábia', heróica ou sibilina: é uma pose (...)". BARTHES, Roland. O neutro: anotaçóes de aulas e seminários ministrados no Collège de France, 1977-1978 (texto estabelecido, anotado e apresentado por Thomas Clerc). Trad. Ivone Castilho Benedetti. São Paulo: Martins Fontes, 2003 (do original em francês Le Neutre, 2002), p. 58. 
sonoro. Questionado por um aluno se haveria ou não uma "máquina silêncio", ${ }^{20}$ Deleuze responde:

(...) do silêncio eu sobretudo não faria uma máquina; para mim, é certo que o silêncio é um elemento criador e um dos mais criadores, fazendo parte da máquina musical; não há absolutamente silêncio fora da máquina musical (...) eu diria que podemos perfeitamente definir o silêncio, mas só podemos defini-lo no interior da máquina musical. ${ }^{21}$

No interior de uma música, portanto, o silêncio surgiria como uma das importantes forças responsáveis por novas conexôes. Poderíamos transpor esta ideia para a poesia e pensar que o silêncio, só existindo enquanto uma força no interior do poema, seria algo definido em relação às palavras, ou nas relaçóes que se fazem entre elas, como vimos primeiramente a partir do procedimento de repetição em Siscar. Na poesia, portanto, o silêncio é criado nos mais distintos procedimentos dos poetas, como se, a partir de diferentes recursos, os poetas tornassem sensível este tipo de força, que é uma força silenciosa - e que, no caso do poema, é justamente a força do silêncio da palavra, do significado, da proposição. Se Cage falava de um silêncio entre as notas, podemos pensar num silêncio entre as palavras, entre as frases ou versos.

O problema que se colocaria ao poeta neste sentido é aquele de tornar sensível o silêncio da linguagem, fazer com que este silêncio, apresentando-se enquanto tal, seja o disparador de uma vertigem poética, como afirma Siscar:

20 "Máquina” é um conceito da filosofia de Deleuze e Guattari, utilizado desde $O$ anti-Édipo, que será cada vez mais substituído pelo de agenciamento, principalmente em Mil platôs. Máquina ou agenciamento são portanto sinônimos, e ambos implicam na ideia da reunião de elementos heterogêneos relacionados por múltiplas forças de atração e repulsão, sístoles e diástoles, sem que haja um fator unificador que coordene tais forças. Neste sentido, há infinitos tipos de máquinas ou agenciamentos, de corpos, gestos, cantos, enunciação, literários, sonoros, pictóricos etc.

21 “(...) du silence je n'en ferais surtout pas une machine; pour moi, il va de soi que le silence est un élément créateur et un des plus créateurs, faisant partie de la machine musicale; il n’y a absolument pas de silence hors de la machine musicale. (...) je dirais qu'on peut parfaitement définir le silence, mais on ne peut le définir qu’à l'intérieur de la machine musicale”. DELEUZE, Gilles. "Sur la musique", aula de 08/07/77, transcriçáo. In: www.webdeleuze. com (acesso em 29/07/2011). 
Silêncio é uma palavra que uso para dizer uma vertigem, ou um enigma. O silêncio é digno de poesia quando, num determinado momento, ele se apresenta destituído de sentido, de intencionalidade, de historicidade - única maneira de apresentar o mundo como se fosse pela primeira vez. Há vertigem poética quando o silêncio se apresenta enquanto tal. ${ }^{22}$

O silêncio, o não-dito, ou o enigma, aparece enquanto tal e provoca a vertigem poética: um olhar que vislumbra algo pela primeira vez, que se depara com algo ainda não conhecido, não nomeado. $\mathrm{O}$ silêncio aparece como o avesso da memória, o que a nega, ou ainda, a memória como aquilo que debela ou captura o silêncio:

O silêncio chega sempre de surpresa de dentro
das coisas que se olham esquecendo que se vê
este receio inexplicável das tardes vazias
é o anúncio e a prova de sua incerta presença
cada tarde à revelia dos livros que nos cercam
dos versos que se vivem sem nenhuma discrição
uma plácida ignorância ganha aquele que tem medo
abole o contorno das coisas sólidas e dos rios
ignorância de tudo da própria humanidade
indiferença ao sopro da velha indiferença
viver em adiamento ouvindo passos de pássaros
mas quando se adia todo o resto que náo houve
quando a frase arrasta suas próprias incertezas
já o alarde da memória debelou o silêncio ${ }^{23}$

O silêncio é vertigem, abismo, quando ele nos surpreende, o que pode acontecer a qualquer instante, mesmo no meio das coisas já tão habituais e cotidianas. Silenciada, ali a linguagem está sem história, sem memória, sem clichês, sem formas pré-definidas. Ela parece então falar do nascimento de todos

22 MALUFE, op. cit., p. 243-244.

23 SISCAR, 2003, op. cit., p. 97. 
os minutos, da irrupção do futuro acontecendo a cada instante. A vertigem é, assim, o momento em que o poema consegue tornar presente um abismo, uma conexão inédita ou, se quisermos retomar Blanchot, consegue "tornar sensível a queimadura da morte": ver uma paisagem pela primeira vez, ouvir um som nunca antes ouvido, deparar-se com algo ainda não nomeado, com um som jamais escutado, uma imagem inusitada, um vazio, um susto, um relâmpago.

Parece-me que, em Siscar, estamos diante deste tipo de vertigem, que nos toma diante da irrupçáo de uma conexáo inusitada; momento em que algo se liga a algo com o qual ele nunca tinha se ligado antes. Mas se a vertigem é, desse modo, o efeito de um nascimento, como explicar que ela seria, ao mesmo tempo, o efeito da queimadura da morte? Neste ponto, é preciso entender a morte náo enquanto fim, mas enquanto futuro: o improvável, o impossível, o imprevisto por excelência. Voltamos aqui à concepção de Blanchot, para quem a morte seria o futuro sempre futuro: espécie de futuro absoluto, ou ainda, de futuro que jamais se torna presente para aquele que morre - e é neste sentido que é preciso entender o abismo, o extremo, como viemos vendo. A morte como a "indeterminação absoluta", como diz Peter Pál Pelbart, um abismo sem fundo "da ordem da incerteza, do excesso, da indecisão do que nunca chega, do que nunca cessa de acontecer". ${ }^{24}$ É neste sentido que qualquer ato de criação atualiza o movimento de nascimento e de morte, repetindo, diferentemente a cada vez, o fato de que novas conexóes, sempre inusitadas, acontecem a todo momento, em um escoamento ininterrupto.

Daí a vertigem: vislumbrar o abismo em que algo improvável parece se delinear, em que somos colocados na beira de um despenhadeiro, prestes a sermos surpreendidos pela irrupção de algo imprevisto. Daí a vertigem ou o naufrágio a que a poesia deveria nos expor, segundo Siscar:

Eu acho que pra mim o que interessa em poesia é essa capacidade que ela tem de abalar as coisas. Essa capacidade que ela tem de ser uma espécie de interrupção, de colapso na experiência

24 PELBART, Peter Pál. O tempo não-reconciliado - imagens de tempo em Deleuze. São Paulo: Perspectiva, 1998, p. 102. Se quiséssemos ser fiéis ao termo usado por Pelbart, teríamos de dizer "morrer", ao invés de morte: o autor faz uma distinção os termos, para marcar o morrer como a morte tal a concebe Blanchot como este incessante, futuro sempre futuro, puro campo de virtualidades. 
costumada do cotidiano, o momento em que alguma coisa entra em colapso, e afunda, um naufrágio, que eu acho que é bem característico da poesia, o que me interessa. ${ }^{25}$

O silêncio do não-dito ou do que não se diz é algo da natureza deste naufrágio ou desta vertigem em que, subitamente, um espaço em branco se abre, pois nele nada está pré-definido ou pré-formado. Ele é da natureza de um lapso, não-senso. É como se ele fosse uma brecha que o poeta cria, um furo na superfície das palavras, para permitir a irrupção destas conexões improváveis, imprevistas mesmo no seu plano inicial de escrita. $\mathrm{O}$ silêncio como um espaço aberto ao qual o poema nos convida.

\section{LA POÉTIQUE DU SILENCE CHEZ MARCOS SISCAR}

\section{RÉSUMÉ}

L'article présente la conception de silence contenue dans la poétique de Marcos Siscar (1964-) à partir du dialogue avec des penseurs et artistes du XXème siècle: un silence de l'excès, dans la place du silence transcendent et intangible des poésies romantique ou métaphysique. L'objectif est montrer la puissance que cette modification de paradigme du silence poétique nourrit la lecture de son poème.

MOTS CLÉS: poésie contemporaine, Marcos Siscar, silence.

Recebido em: 22/03/12

Aprovado em: 27/11/12

25 SISCAR, Entrevista para o programa Entrelinhas, op. cit. 